University of Nebraska - Lincoln

DigitalCommons@University of Nebraska - Lincoln

March 1985

\title{
Lung Cancer Incidence in a Chinese High Background Area - Epidemiological Results and Theoretical Interpretation
}

\author{
Werner Hofmann \\ Max-Planck-Institut für Kernphysik, Werner.Hofmann@mpi-hd.mpg.de \\ Robert Katz \\ University of Nebraska-Lincoln, rkatz2@unl.edu \\ Chunxiang Zhang \\ Zhongshan University
}

Follow this and additional works at: https://digitalcommons.unl.edu/physicskatz

Part of the Physics Commons

Hofmann, Werner; Katz, Robert; and Zhang, Chunxiang, "Lung Cancer Incidence in a Chinese High Background Area - Epidemiological Results and Theoretical Interpretation" (1985). Robert Katz Publications. 129.

https://digitalcommons.unl.edu/physicskatz/129

This Article is brought to you for free and open access by the Research Papers in Physics and Astronomy at DigitalCommons@University of Nebraska - Lincoln. It has been accepted for inclusion in Robert Katz Publications by an authorized administrator of DigitalCommons@University of Nebraska - Lincoln. 
Published in THE SCIENCE OF THE TOTAL ENVIRONMENT 45 (1985), pp. 527-534.

Copyright (c) 1985 Elsevier Science BV. Used by permission.

Special Issue: Exposure to Enhanced Natural Radiation and Its Regulatory Implications

Proceedings of a Conference held in Maastricht, The Netherlands, March 25-27, 1985

LUNG CANCER INCIDENCE IN A CHINESE HIGH BACKGROUND AREA - EPIDEMIOLOGICAL RESULTS AND THEORETICAL INTERPRETATION

W. HOFMANN ${ }^{1}$, R.KATZ ${ }^{2}$ and ZHANG Chunxiang ${ }^{3}$

$1_{\text {Division of Biophysics, University of Salzburg, A-5020 Salzburg (Austria) }}$

${ }^{2}$ Department of Physics, University of Nebraska, Lincoln, NE 68588 (USA)

${ }^{3}$ Department of Physics, Zhongshan University, Guangzhou (China)

\section{ABSTRACT}

A survey of inhabitant exposures arising from the inhalation of radon and thoron daughters, and lung cancer mortality has been carried out in two adjacent areas in Guangdong province, China, designated as the "high background" and the "control" area. Annual exposure rates are $0.38 \mathrm{WLM} / \mathrm{yr}$ in the high background, and $0.16 \mathrm{WLM} / \mathrm{yr}$ in the control area, while age-adjusted mortality rates are 2.7 per $10^{5}$ living people of all ages in the high background, and 2.9 per $10^{5}$ in the control area. From this data we conclude that we are unable to determine the excess lung cancer rate over normal fluctuations below a cumulative exposure of about 15 WLM. This conclusion is supported by lung cancer mortality data from an Austrian high background area.

\section{INTRODUCTION}

Although human beings are exposed to low levels of ionizing radiation during their entire lifetime, only rough and controversial information can be derived from epidemiological investigations, typically because of the synergistic interference of other environmental co-carcinogens, e.g. cigarette smoke. Their interference can be minimized by the study of exposures at higher dose levels, such as uranium miner data, or of predominantly non-smoking populations relatively well isolated from industrial pollution. In using the data for occupational exposure in uranium mines to derive the lung cancer risk for low level environmental exposure, one must consider the significant environmental and physiological differences between the two exposure situations, suggesting that the members of the general public may be at a lower risk per unit exposure than miners (ref.1). Thus epidemiological data from non-polluted high background areas, where the natural radiation exposure is high and the natural lung cancer incidence is low, would offer the unique chance to check current risk estimates for domestic radon daughter exposure. Such a high background area has been found in China.

EPIDEMIOLOGICAL RESULTS FROM A CHINESEHIGH BACKGROUND AREA

A survey of inhabitant exposures arising from the inhalation of ${ }^{222} \mathrm{Rn}$ (radon) and ${ }^{220} \mathrm{Rn}$ (thoron) and their short-lived decay products, and lung cancer morta- 
lity has been carried out by the Chinese group (ref.2,3) since 1970, in two adjacent areas in Guangdong province, China, designated as the "high background" and the "control" area. Both of these areas are predominantly rural with stable populations that have lived in the same area for generations. The population in each area is about 80,000 . In this region of China women typically do not smoke.

The average concentrations of radon, indoor and outdoor, in the high background area are 29.9 and $16.3 \mathrm{~Bq} / \mathrm{m}^{3}$, factors of 2.3 and 1.5 times the concentrations in the control area, respectively. The average concentrations of thoron, indoor and outdoor, in the high background region are 167.6 and $18.5 \mathrm{~Bq} / \mathrm{m}^{3}$, factors of 9.6 and 4.8 times the concentrations in the control area (ref.4,5). The average potential alpha energies in the high background area are $4.7 \mathrm{mWL}$ (outdoor) and $5.2 \mathrm{mWL}$ (indoor) for radon progeny, and $2.8 \mathrm{mWL}$ (outdoor) and $11.7 \mathrm{mWL}$ (indoor) for thoron progeny. In the control area, the average potential a]pha energies are $2.5 \mathrm{mWL}$ (outdoor) and $2.2 \mathrm{mWL}$ (indoor) for radon progeny, and $1.3 \mathrm{mWL}$ (outdoor) and $3.9 \mathrm{mWL}$ (indoor) for thoron progeny.

Using these potential alpha energies and an indoor occupancy factor of 0.5 , the exposure rates from radon daughters only are $0.26 \mathrm{WLM} / \mathrm{yr}$ in the high background area, and $0.12 \mathrm{WLM} / \mathrm{yr}$ in the control area. Inhalation of thoron daughters also contributes to the absorbed dose in bronchial tissue, although its effective dose equivalent per unit inhaled potential alpha energy is only about one third of the corresponding value for the short-lived radon daughters (ref.6,7). Taking into account a weighted additional exposure from thoron daughters ( $1 \mathrm{WLM}(T n)=0.33 \mathrm{WLM}(\mathrm{Rn})$ to give the same dose equivalent), the total riskrelevant annual exposure to radon and thoron daughters is $0.38 \mathrm{WLM} / \mathrm{yr}$ in the high background area, and 0.16 WLM/yr in the control area. This gives then a ratio of the exposure rate from radon and thoron daughters in the high background area to that in the control area of 2.4 .

In fourteen years of continuousstudy, from 1970 to 1983 (ref.8), the accumulated population surveyed in the two areas is nearly equal being 764,696 person years in the high background area, and 777,482 person years in the control area. Lung cancer deaths were found to be 23 in the high background area, and 27 in the control area, with a ratio of men to women being 1.7 in the high background, and 1.3 in the control area. Annual mortality rates adjusted according to age and sex are 2.7 per $10^{5}$ living people of all ages in the high background and 2.9 per $10^{5}$ in the control area. This difference in mortality rates is not statistically significant. Even in such rural areas, relatively free from industrial pollution, having stable populations with comparable smoking habits, we are unable to determine the excess lung cancer risk over normal fluctuations at an exposure level of $0.38 \mathrm{WLM} / \mathrm{yr}$. 
EPIDEMIOLOGICAL RESULTS FROM AN AUSTRIAN HIGH BACKGROUND AREA

The exposure rate from radon daughters and lung cancer incidence in the radon spa Badgastein, Austria have been studied by Pohl-Rïling et al. (ref.9). Most of the Badgastein inhabitants receive a mean exposure of approximately $0.4 \mathrm{WLM} / \mathrm{yr}$ which is about twice the value of a normal environment exposure in Salzburg province. The annual lung cancer incidence rate for Badgastein is 30 per $10^{5}$ living people of all ages, not statistically different from the observed lung cancer rate in the whole province of Salzburg of 32 per $10^{5}$. Although the mean exposure in Badgastein is twice that in the province, the lung cancer mortality rate is again not increased. While the corresponding high background and control areas in Austria and China have approximately the same exposure rates, the incidence rate of lung cancer in these areas is, however, about one order of magnitude higher than in the corresponding areas of China.

Consistent with the Chinese and Austrian experience, relatively clear differences in radon exposure, ranging from 0.29 to $1.5 \mathrm{WLM} / \mathrm{yr}$ were not reflected in the geographical distribution of the lung cancer incidence in Finland (ref.10),

\section{RISK ANALYSIS}

An estimate of lung cancer risk at these environmental exposure levels can be obtained from BEIR-III (ref.11) by using a risk of 10 cases per $10^{6} \mathrm{PV}$ per WLM for age group $35-49,20$ cases per $10^{6}$ PY per WLM for age group 50-65, and 50 cases per $10^{6}$ PY per WLM for age 65 and over, with a minimum latent period of 10 years before risk becomes effective. Below age 35 no excess risk has been assumed.

The risk estimate based on BEIR-III yields an expected number of 2.9 cases/yr of excess lung cancer cases in the high background area, while 1.6 total lung cancers per year are observed. The BEIR-III based estimate for the control area is 1.5 cases/yr of excess lung cancers, while the total number of annual lung cancers is 1.9 .

Similar risk estimates can be derived from UNSCEAR (ref.12) and BEIR-II (ref.13), referring essentiallyto mining populations, and Evans et al. (ref.1), referring specifically to the members of the general public.

The linear extrapolation used by BEIR-II, BEIR-III, and UNSCEAR to estimate the number of excess lung cancers leads at the average to a slight overestimate of the total number of observed lung cancers, while the smaller numbers derived from Evans et al (ref.1) are compatible with the observed total lung cancer cases.

Besides the fact that no excess lung cancers have been found in the chinese high background area, there is the additional fact that the total lung cancer incidence in both Chinese areas is about an order of magnitude lower than in other countries (even the Chinese average is about twice this value, being 5.0 
per $10^{5}$ persons). This finding may be due to two reasons:

(1) Cigarette smoking is considered to be the primary cause for lung cancer induction. Analyses of lung cancer mortality data of American and Czech miners suggest a strong multiplicative effect of cigarette smoking and exposure to radon decay products (ref.14). Since mortality rates for men and women in the two Chinese areas are similar (the percentage of smokers is the same in both areas, being about $38 \%$ ), contrary to the experience in other countries, and women there typically do not smoke, we are led to the suggestion that cigarette smoke is less effective in these populations, e.g. because of differences in smoking habits or tobacco compounds. Assuming that the Chinese population in these areas consists mainly of "non-smokers" and applying the relative risk function for non-smokers given by Whittemore and McMillan (ref.14) to published lung cancer rates for non-cigarette smokers, no excess lung cancer risk will be obtained for the high background area. The lung cancer rates for non-smokers are, however, still slightly higher than the average annual lung cancer rate in both Chinese areas at the same exposure level.

(2) Next to cigarette smoking, the most important cause of lung cancer is probably general air pollution. Cohen and Cohen (ref.15) conclude that the lung cancer rate in advanced countries early in this century, before the steep rise in lung cancer risk in recent years, was $10-40 \times 10^{-6} / \mathrm{yr}$. This number is comparable to the Chinese results, suggesting that the low lung cancer incidence in these rural, non-polluted areas is partly due to missing industrial pollution.

From this analysis we conclude that we might characterize these Chinese populations as mainly "non-smoking" populations, living in a relatively unpolluted environment. We are, therefore, led to the suggestion that the Chinese lung cancer rates in both areas represent a "pure" radiation effect. This is consistent with the assumption that the excess lung cancers can be conservatively estimated from the average number of total lung cancers in the control and high background areas in China.

\section{THEORET ICAL INTERPRETATION OF EPIDEMIOLOGICAL DATA}

In first approximation low dose effects of alpha particles arise from the interaction of isolated charged particles with sensitive biological targets. The low dose problem thus reduces to one of understanding the structure of a particle track in biological matter for the required variety of end-points, especially for radiation-induced carcinogenesis. Since transformation and carcinogenes is can only take place in surviving cells, the observed tumor frequency always represents the product of two probabilities, that for malignant transformation and that for not being killed. Thus the general form of the incidence function $F(D)$ as a function of dose $D$ is given by (ref.11): 
$F(D)=\left(\alpha_{0}+\alpha_{1} D+\alpha_{2} D^{2}\right) \exp \left(-\beta_{1} D-\beta_{2} D^{2}\right)$

Formamalian cell killing, track theory and experimental radiosensitivity parameters allow us to construct schematic models of track structure in a biological medium (ref.16). For a given dose $D(D=F x L)$ delivered by the fluence $F$ of alpha particles with linear energy transfer $L$, the number of surviving cells $N$ in a tissue volume consisting of $N_{0}$ cells can be expressed by:

$N / N_{0}=\exp \left(-P \sigma_{0} F\right)$

where $P$ is the probability of an ion of atomic number $Z$, effective charge number $z^{*}$, moving at speed $\beta$ relative to the speed of 1 ight, to inactivate a cell whose nucleus it threads, and $\sigma_{0}$ is the plateau value of the extrapolated cross-section which approximates the geometrical cross-section of the cell nucleus. Equation (2) refers to the action of a single incident particle (ion ki11).

Since we do not have radiosensitivity parameters for human bronchial epithelial cells, we assume that human T-1 kidney cells are representative of human lung cells. The use of different parameters more suitable for other cell lines or experimental conditions would not change substantially the calculated inactivation probabilities or the implications of these calculations.

To assess biological radiation effects in the lungs, we assume that the initial radiation damage at the organ level represents an accumulation of effects arising in single cells. It has generally been found that the effect of modifying factors is reduced for high LET radiations, at least for cellular inactivation. More complex disease mechanisms, such as malignant transformation or carcinogenesis, require a complete mechanistic understanding which is currently still too fragmentary. Since we do not know the function of carcinogenic risk expression from initial cellular effects to an observable tumor, we cannot apply a track structure analysis as has been found practicable for cell killing. We therfore seek to find an induction or transformation function per surviving cell, assuming that it is proportional to $D^{n}$, by fitting epidemiological data for lung cancer incidence. Taking into account the above derived survival function, the incidence function adopts the form of:

$F(D)=k D^{n} \exp \left(-P_{0} D / L\right)$

Because of the large uncertainties associated with the epidemiological lung cancer data (ref.17), a more sophisticated functional form would be inappropriate at the current stage of our knowledge of carcinogenesis.

For the fitting procedure we adopt a dose-exposure conversion factor of 0.5 
$\mathrm{rad} / \mathrm{WLM}$, to be the same for uranium miners and the general public. For a mean basal cell depth of about $40 \mu \mathrm{m}$ in segmental and subsegmental bronchioles we calculate a mean track length of alpha particles emitted from airway surfaces of about $50_{\mu} \mathrm{m}$. Weighting the contributions of ${ }^{218}$ Po and ${ }^{214}$ Po alpha particles we derive a mean LET of about $150 \mathrm{keV} / \mathrm{mm}$, having an inactivation probability in $\mathrm{T}-1$ cells $\left(\sigma_{0}=5.4 \times 10^{-7} \mathrm{~cm}^{2}\right.$ ) of 0.35 .

The results of least square fits are presented in Fig. 1. The data points shown in this figure are taken from Jacobi (ref.18), comprising data on U.S. miners, Czech miners, and Canadian miners, and do not represent all data available (the missing data would not change significantly the above pattern). It also includes the total number of lung cancer cases in the Chinese high background areas. The fits assign the values of $30.2(n=1)$ and $0.11(n=2)$ to the proportionality constant $k$ to get the excess lung cancer cases per $10^{6}$ person years and per WLM, if the dose is expressed in WLM.

If we incorporate the Chinese high background data, then the best fit to the data is obtained from an assumption of quadratic $(n=2)$ response for induction per surviving cell. The quality of the data, however, does not allow us to rule out the linear $(n=1)$ response. Since neither hypothesis can be falsified at our stage of knowledge, both extrapolations seem to be equally acceptable. Scientific evidence can be supplied to support either hypothesis:

Large scale experiments with rats suggest linearity even at exposures as low as 20 WLM, consistent with animal experiments at much higher exposures (ref.19). Since similarities exist between dose-effect relationships in man and animal over a wide range of exposures (ref.20), one might also expect a linear-exponential response in humans, at least down to about 20 WLM.

on the other hand, in chemical carcinogenesis it has been suggested for a long time that at least a two-hit process is required for the production of a promotion-independent cell (ref.21,22). Burch (ref.23) also advanced arguments in support of a tentative view that bone cancer is initiated by a highly specific two-mutation mechanism. This agrees e.g. with results of Rowland et al. (ref.24) that a dose-squared-exponential function described best the incidence of bone sarcoma of female radium dial painters exposed to ${ }^{228} \mathrm{Ra}$ and ${ }^{226} \mathrm{Ra}$.

\section{CONCLUSIONS}

Assuming a cumulative exposure over a 40 year period at a mean exposure rate of $0.38 \mathrm{WLM} / \mathrm{yr}$, we conclude from the Chinese data that there is no observable excess lung cancer risk below a cumulative exposure of about 15 WLM. We are in the region of "background noise" and cannot determine the excess cancers. This finding is consistent with the fact that all epidemiological studies have failed so far to demonstrate an excess risk from doses up to 10 rad above background (ref. 25). 


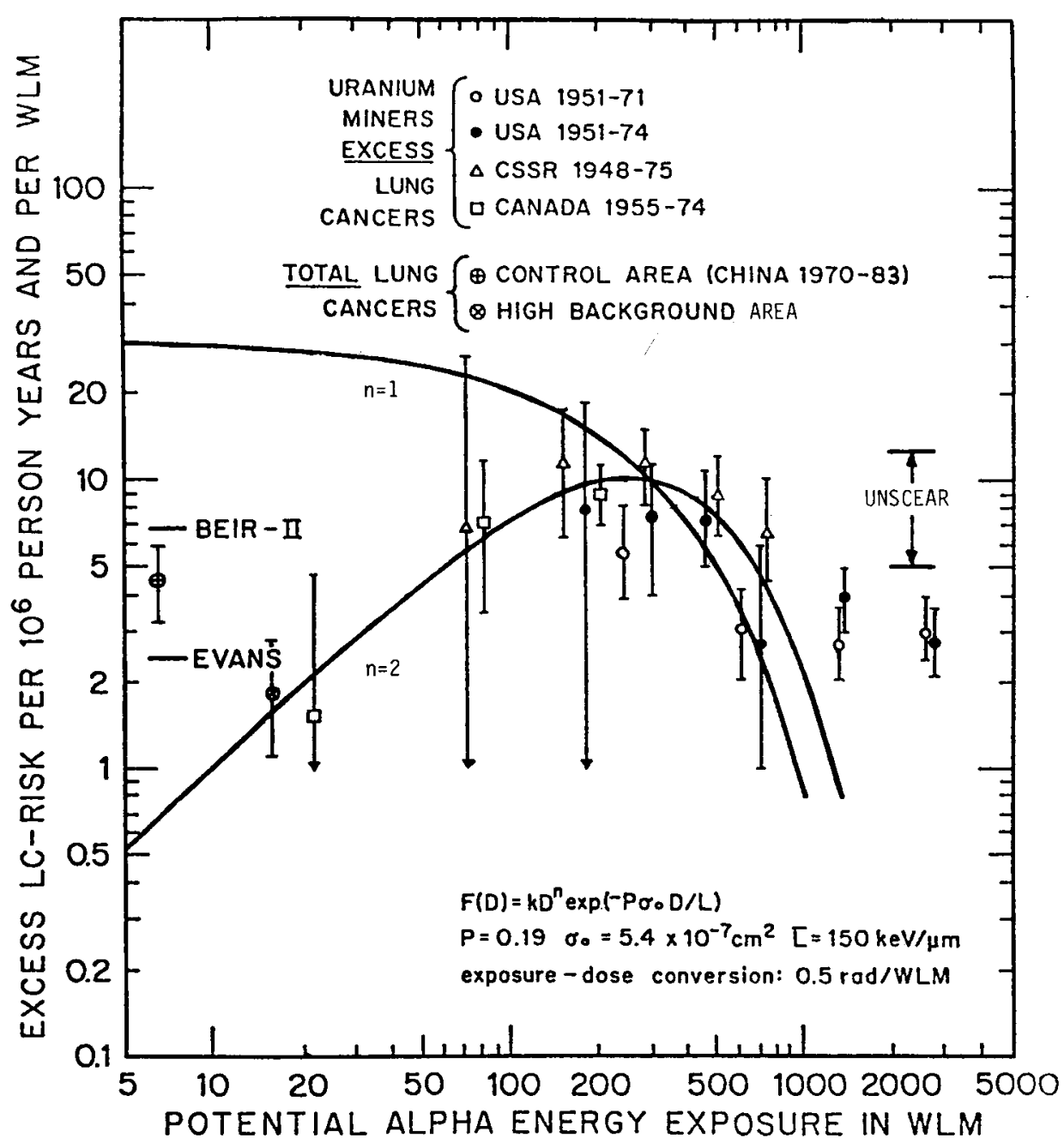

Fig. 1. Excess lung cancer risk in uranium miners and total lung cancer risk in the inhabitants in high background and control areas in China per WLM vs. cumulative exposure to radon and thoron decay products in WLM.

The low lung cancer incidence in both Chinese areas, for a mainly "non smoking" population in a relatively unpolluted environment, suggests that the Chinese lung cancer rates represent a "pure" radiation effect. We therefore may take the total lung cancers and interpret them as the radiation-induced excess cancers.

A theoretical analysis of lung cancer data reveals that the best fit to the Chinese data is obtained by a quadratic-exponential response function. Since the 
uncertainties associated with the epidemiological data do not allow us to rule out a linear-exponential relationship, the best estimate may lie between both functional forms, suggesting a more complex response function. If a linear extrapolation is to be used, the Chinese data support the upper bound for a lifetime risk due the environmental radon given by Evans et al. (ref.1) of $10^{-4}$ per WLM.

\section{ACKNOWLEDGEMENT}

This work is supported by the U.S. Department of Energy.

\section{REFERENCES}

1 R.D.Evans, J.H. Harley, W. Jacobi, A.S. McLean, W.A. Mills and C.G. Stewart, Nature, 290 (1980) 98-100.

2 High Background Radiation Research Group, China, Science, 209 (1980) 877-880.

3 High Background Radiation Research Group, China, Chin. J. Radio1. Med.Prot., 2 (1982) 9-15.

4 High Background Radiation Research Group, China, Radiol. Med. Prot. 2 (1978) 27 (in Chinese).

5 Zhang Zhonghou, Lu Zhizhao, Teng Weifang, Zhang Chunxiang, Yu Zhengfang, Guan Zujie, Wu Zenghan, Chen Zizheng, Liao Yinying, Shen Hong, Ye Jida and $\mathrm{Ni}$ Jindi, Chin. Radiol. Med. Prot., 2 (1982) 27-33.

6 International Commission on Radiological Protection, ICRP Publication 32, Annals of the ICRP, 6 (1981) No. 1.

7 United Nations Scientific Committee on the Effects of Atomic Radiation, Ionizing Radiation: Sources and Biological Effects, United Nations, New York, 1982.

8 Zhai Shaojian, Lin Xiujian, Fan Tianmei, He Weihu, Feng Ruilin, Chen Maozhao, Li Shihua, Chen Lin, Li Rangbo and Ye Huanxiang, Chin. J. Radiol. Med. Prot., 2 (1982) 48-51.

9 J. Poht-Rüling, E. Pohl, F. Steinhäusler and F. Daschil, Médecine Biologie Environment, 10 (1982) 13-17.

10 0. Castren, K. Winqvist, I. Makelainen and A. Voutilainen, Radiat. Prot. Dosim., 7 (1984) 333-336.

11 National Academy of Sciences, The Effects on Population of Exposure to Low Levels of Ionizing Radiation, Washington D.C., 1980.

12 United Nations Scientific Committee on the Effects of Atomic Radiation, Sources and Effects of Ionizing Radiation, United Nations, New York, 1977.

13 National Academy of Sciences, The Effects on Population of Exposure to Low Levels of Ionizing Radiation, Washington D.C., 1972

14 A.S. Whittemore and A. McMillan, J. Nat1. Cancer Inst., 71 (1983) 489-499.

15 A.F. Cohen and B.L. Cohen, Heal th Phys., 38 (1980) 53-69.

16 R. Katz and W. Hofmann, NucT. Instr. Meth., 203 (1982) 433-442.

$17 \mathrm{~F}$. Steinhäusler and W. Hofmann, in Proc. Int. Conf. on Occupational Safety in Mining (in press).

18 W. Jacobi, M. Gomez (Ed.), Proc. Radiation Hazards in Mining: Control, Measurement and Medical Aspects, Amer. Inst. Mining, Metallurgical and Petroleum Engrs. Inc., New York, 1981, pp. 503-510.

19 J. Chameaud, R. Masse and J. Lafuma, Radiat. Prot. Dosim., 7 (1984) 385-388.

20 National Council on Radiation Protection and Measurements, NCRP Report No.78 NCRP, Bethesda, 1984.

21 P. Armitage and R. Doll, Brit. J. Cancer, 11 (1957) 161-169.

22 V.R. Potter, Yale J. Biol. Med., 53 (1980) 367-384.

23 P.R.J. Burch, Nature, 185 (1960) 135-142.

24 R.E. Rowland, A.F. Stehney and H.F. Lucas Jr., Radiat. Res., 76 (1978)368-383

25 H.I. Kohn and R.J.M. Fry, New Eng1. J. Med., 310 (1984) 504-511. 